\title{
Assessment of the energy content of human milk administered to very low birth weight infants
}

\author{
Alan A. Vieira, ${ }^{1}$ Maria E. L. Moreira, ${ }^{2}$ Adriana D. Rocha, ${ }^{3}$ \\ Hellen P. Pimenta, 4 Sabrina L. Lucena 4
}

\begin{abstract}
Objective: To evaluate and compare the energy content in fresh and processed human milk administered to very low birth weight infants born in the Institute Fernandes Figueira.

Methods: Samples of $0.5 \mathrm{ml}$ of fresh and processed human milk were evaluated as for the fat percentile and energy content, which was calculated by mathematical formulas. Four hundred and sixty two human milk samples were analyzed, 401 of processed human milk and 61 of fresh human milk.

Results: The median and the standard deviation of the fat percentile checked was $2.9 \pm 1.2 \%$ in the processed samples and $8.9 \pm 4.6 \%$ in the fresh samples $(p<0.001)$. The median and the standard deviation of the energy content calculated was $53.6 \pm 7.2 \mathrm{kcal} / 100 \mathrm{ml}$ in processed samples and $85.9 \pm 27.9 \mathrm{kcal} / 100 \mathrm{ml}$ in fresh samples ( $p<0.001$ ).

Conclusion: The processed human milk samples had less energy content and less fat than fresh human milk samples suggesting that the complex processes of the human milk manipulation and administration can determine losses in energy content.
\end{abstract}

J Pediatr (Rio J). 2004;80(6):490-4: Low birth weight, human milk, calories.

\section{Introduction}

Human breast milk is the ideal food for any newborn infant because of its digestibility, balanced chemical composition and capacity to generate immunity. ${ }^{1}$ Its use has been greatly encouraged in neonatal intensive care units (NICU), including both milk extracted from the mother's breast and immediately administered to the newborn infant (fresh or raw human milk - RHM) and milk that has been stored in a milk bank (processed human milk - PHM).

1. Doctoral student, Graduate Program in Mother and Child Health, Instituto Fernandes Figueira (IFF), Rio de Janeiro, RJ, Brazil.

2. Ph.D. Researcher, IFF, Rio de Janeiro, RJ, Brazil.

3. M.Sc. IFF, Rio de Janeiro, RJ, Brazil.

4. Speech therapist.

Manuscript received Mar 24 2004, accepted for publication Sep 222004.

Suggested citation: Vieira AA, Moreira ME, Rocha AD, Pimenta HP, Lucena SL. Assessment of the energy content of human milk administered to very low birth weight infants. J Pediatr (Rio J). 2004;80:490-4
In cases in which a mother finds herself separated from her child or when a baby is incapable of suckling at the breast, the collection and stocking of human breast milk has been stimulated. ${ }^{2}$

Nevertheless, the use of exclusive human milk to feed very low birth weight newborns (VLBW) infants has been associated with inadequate weight gain and nutritional deficit during hospitalization. ${ }^{3}$ A number of different causes may contribute to this poor performance, primarily the large variety in lipid content. This variability is related to the methods used to collect, store and administer human milk, among other reasons. ${ }^{2,3}$

The employment of strategies that can test the energy content of human milk at neonatal centers could contribute to its being maintained as the food source of choice for babies avoiding the use of formula.

The most commonly used method for determining the energy content of human milk, the creamatocrit technique, was proposed by Lucas in 1978 and adapted by Wang et al. 
in 1999, and consists of centrifuging milk samples, measure the quantity of fat that is present and, by means of mathematical calculations, determine its energy content. 4,5

The objective of this study is to assess and compare the energy content of the RHM and PHM given to VLBW infants at the Instituto Fernandes Figueira (IFF).

\section{Methodology}

During the period from January to October in 2003, samples of RHM (mature milk produced after the 14th day of lactation) and PHM were assessed as administered to VLBW infants in weight gain phase with no active diseases and clinically stable.

Samples were collected from all of the human milk (both types RHM and PHM) offered to preterm infants at times between 9 and 15 hours, the period during which the greatest number of mothers are present at the NICU of the IFF.

The PHM samples were collected from the receptacles sent to the NICU immediately before being offered to the newborn infant; the milk, therefore, had been collected, pasteurized and frozen at the human milk bank and, at a later date, sent to the lactation center, being defrosted, heated, distributed and supplied to the NICU. Milk samples that presented coagulation to the naked eye were discarded. Before collection, homogenization of the material was performed with manual movements as recommended by Wang et al. ${ }^{4}$

The RHM samples were collected by means of manual expression from the breast, after the newborn infant had suckled for 10 minutes or, if the baby was not yet capable of suckling, after 10 minutes' manual expression (intermediate milk). These samples were collected directly from the breast as soon as a thick drop was produced.

All samples (RHM and PHM) were taken in triplicate (each in the form of $0.5 \mathrm{ml}$ of human milk - three glass capillaries: $75 \times 1.5 \mathrm{~mm}$ ) and immediately centrifuged for

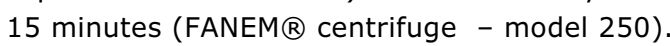

The method employed to determine the energy content of the human milk samples consists of centrifuging samples of milk, measure the quantity of cream (fat) that is present and, by means of particular mathematical calculations, determine its energy content. ${ }^{4,5}$ The mathematical formulae employed for the energy calculations used for the milk samples are as follows:

- Raw Milk: energy (kcal/dl) $=5.99 \times$ creamatocrit (\%) +32.5 ;

- Frozen Milk: energy $(\mathrm{kcal} / \mathrm{dl})=6.20 \times$ creamatocrit (\%) +35.1 .

The total column heights and the height of the cream column were measured for every capillary with the use of a pachymeter caliper; in this way the percentage of cream in the whole milk was determined. The same procedure was executed by three different observers, after tests for intraobserver and interobserver agreement had been performed. ( $k=0.94$ and 0.87 , respectively).
Results were discarded if the determination of cream percentage was identified as having been compromised after centrifuging. For example, cream columns that were not well defined or significant discrepancies between the heights of different columns from the same sample.

The caloric contents of RHM and PHM were compared using SPSS 9.0 statistical software and the Kruskal-Wallis non-parametric test.

The study design was approved by the IFF Committee for Ethics in Research, and every participating mother gave formal consent in advance to their inclusion in the study.

\section{Results}

Four hundred and sixty-two samples of human milk were collected: 401 of PHM and 61 of RHM.

The mean, standard deviation and median cream percentages were as follows:

- for the processed milk group: mean was $3 \pm 1.2 \%$ and median was $2.9 \%$;

- for the raw milk group: mean was $8.9 \pm 4.6 \%$ and median was $7.7 \%$.

The difference between means was significant $(p<0.001)$ (Figure 1).

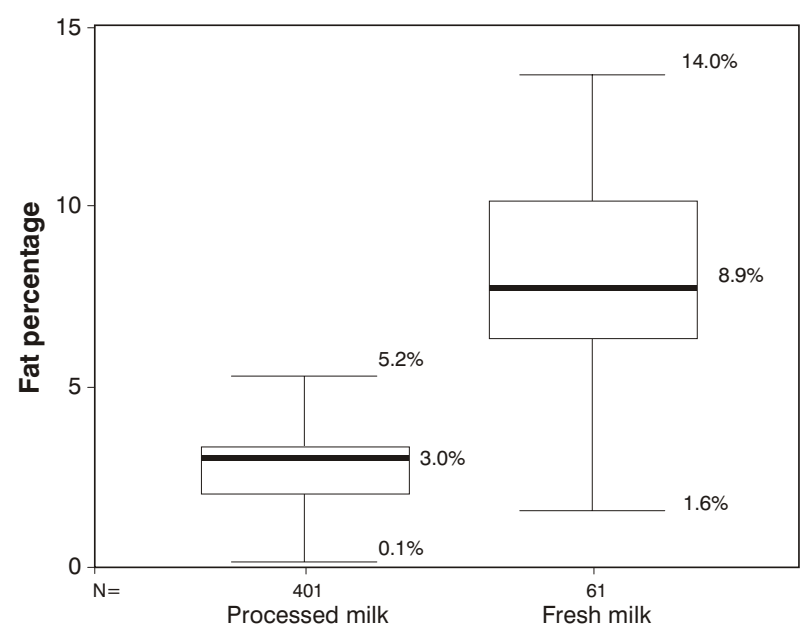

Type of milk

* The highest and lowest values of each figure express the maximum and minimum values; the box represents $50 \%$ of the sample collected; the other $50 \%$ are distributed between the box and the highest and lowest values ( $25 \%$ for each side); the broader line in the box represents the mean.

Figure 1 - Distribution of cream percentages in the groups*

The mean, standard deviation and median of the calculated energy contents were as follows;

- for the processed milk group: mean was $53.6 \pm 7.2 \mathrm{kcal} /$ $100 \mathrm{ml}$ and median was $53.6 \mathrm{kcal} / 100 \mathrm{ml}$; 
- for the raw milk group: mean was $85.9 \pm 27.9 \mathrm{kcal} / 100$ $\mathrm{ml}$ and median was $78.5 \mathrm{kcal} / 100 \mathrm{ml}$.

The difference between the means was significant $(p<0.001)$ (Figure 2).

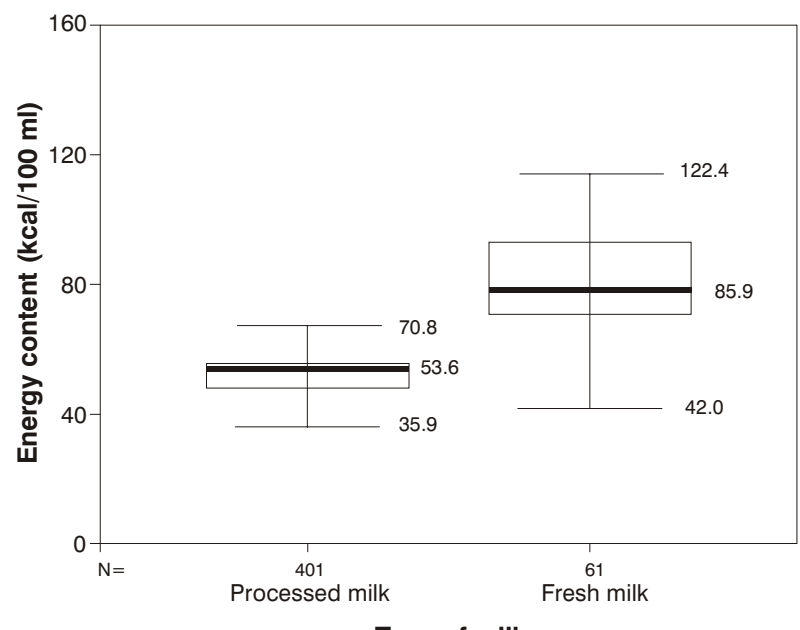

Type of milk

* The highest and lowest values of each figure express the maximum and minimum values; the box represents $50 \%$ of the sample collected; the other $50 \%$ are distributed between the box and the highest and lowest values (25\% for each side); the broader line in the box represents the mean.

Figure 2 - Distribution of the energy content values in the groups*

\section{Discussion}

Human milk is a homogenous mixture that meets the nutritional, metabolic and digestive needs of term infants in addition to providing hormones, essential amino acids and immunological factors, making it the best choice for the nutrition of newborn infants, especially premature and severely ill ones. ${ }^{3}$

Despite innumerable advantages, several different studies have demonstrated that exclusive use of human milk to feed VLBW infants results in reduced growth velocity when compared with artificial formula milk. This fact might be explainable by an insufficient concentration of certain nutrients in human milk, primarily proteins, lipids and electrolytes. 3,6,7 Even in the face of this inadequacy human milk is still recommended for VLBW infants because of the benefits reaped in stimulating the organism's defense mechanisms and the unique profile of its fat content. ${ }^{3}$

In order to remain available to have her milk collected at the time of administration to her baby a mother must overcome a number of difficulties. The high frequency of collections - normally every 2 hours, the inadequate accommodations for the mother during the usually long period of VLBW infants' hospital stay, the possible existence of other children also requiring her care and the absence of nipple stimulation by the newborn infant suckling are all factors making the practice more difficult. ${ }^{8}$ Breast stimulation with massage and periodic pumping soon after the baby's birth, in addition to support from the family and from the health team, are essential to long-term milk production. ${ }^{3}$

Milk collected directly from the mother and given to the baby with no treatment (RHM) is considered by many authors to be the best option for feeding VLBW infants, since in this state it offers a greater concentration of proteins and electrolytes, primarily sodium, chloride, magnesium and iron, in addition to the higher fat content. ${ }^{9-13}$

In a recent study, human milk collected by manual expression immediately before creamatocrit was performed (RHM) exhibited a mean fat percentage of $2 \pm 1.9 \%$ when collected at the start of suckling, $9 \pm 2.8$ after 5 minutes' suckling, $11.4 \pm 4.6 \%$ at the tenth minute and $14.3 \pm 3.8 \%$ at the end. ${ }^{13}$ In the study made of the samples collected at the IFF, the creamatocrit of RHM collected 10 minutes after the start of suckling or after 10 minutes of pumping by manual expression was $8.9 \pm 4.6 \%$. This high level of fat could be explained by the manual pumping of the breast milk and also by the time allowed to pass before collection, since the body fat percentage increases while feeding. 3,13 The caloric content of the RHM was $85.9 \pm 27.9 \mathrm{kcal} / 100 \mathrm{ml}$, which is enough for adequate VLBW infants growth according to American Academy of Pediatrics recommendations. ${ }^{14}$

Some concern may be directed at the possibility of RHM exposing preterm newborn infants to bacteria. There is evidence to prove that human milk maintains its bacteriostatic characteristics unaltered for up to 6 hours if stored at a temperature between 19 and $26^{\circ} \mathrm{C}$ or for up to 48 hours is stored refrigerated, which emphasizes the safety of giving raw milk at the time of collection. 2,15

When the mothers of premature newborn infants are unable to produce milk in sufficient volume to meet the needs of their babies, it becomes necessary to use PHM. ${ }^{8}$ The only type of PHM that is safe to give to premature babies is that provided by milk banks. These are centers specialized in the promotion and encouragement of breastfeeding, that are responsible for the collection, processing and quality control of donated human milk. ${ }^{16,17}$

Before being given to the newborn infants, under prescription, the PHM is exposed to a complex process: prestorage, defrosting, pasteurization, refreezing, re-defrosting and heating. Throughout this process significant energy losses are detected, primarily from the fat content which is the main caloric-energetic source of human milk. 2,3 The pasteurization process does not reduce the nutritional content of human milk, but it does reduce its specific bioactive function. ${ }^{18}$ The process of freezing and defrosting, however, results in the bursting of fat globule membranes resulting in coalescence and facilitating adherence to flask walls and to utensils used to feed the newborn infants (plastic equipment and syringes). $9,12,19-21$ As a consequence of this, if milk is infused by gastric tube, infusion syringes are held horizontally and milk is not homogenized before feeding, losses can reach $34 \%$ of the fat content. 4,22 
In clinical practice, it is not just expected that a preterm infant will exhibit growth velocity similar to that of a fetus or infant of the same post-conceptional age, but great effort is actually employed to achieve this. ${ }^{23}$ This is a great challenge for VLBW infants, since as they are exposed to intense stress for extended periods causing increased calorie requirements. 24,25 A study of the longitudinal growth of preterm newborn infants in hospital, undertaken by Ehrenkranz et al. in 1999, found evidence of great difficulties in mimicking the fetal rate of growth, particularly when adequate nutritional provision is not prioritized. 26

The "nutritional programming" theory states that inadequate nutrition for premature newborn infants or during the early stages of infancy had negative repercussions in adult life and can cause hypercholesterolemia, diabetes and arterial hypertension. ${ }^{27-29}$ When all these concepts are taken in association, constant evaluation of the energy content of the milk offered to premature newborn infants is recommended. 29

The study undertaken of the milk samples collected at the IFF demonstrates that the energy content of intermediate milk extracted at the time it is to be given to the newborn infant (RHM) is superior to $\mathrm{PHM}$, presenting a mean value of $85.9 \mathrm{kcal} / 100 \mathrm{ml}$ in comparison to 53.6 $\mathrm{kcal} / 100 \mathrm{ml}$ for PHM $(\mathrm{p}<0.001)$. Other studies have tested the creamatocrit value in samples of PHM and found it to be lower than in RHM. ${ }^{30-32}$ Wang relates that freezing and defrosting human milk is associated with reductions in the creamatocrit, however the effects of these processes on the lipid, carbohydrate and protein concentrations were not found to be significant. ${ }^{4}$

The calculations made to ascertain the energy content of the PHM samples tested in this study demonstrated that the caloric content of the samples was not the most suitable for guaranteeing the desired nutritional support to VLBW infants. 14

Nutritional support is recognized as one of the principal pillars supporting the treatment of newborn infant. Therefore, assuring the quality of the milk offered to these babies is fundamental to guaranteeing "normal" growth.

Concern over the low rate of weight gain of newborn infants fed exclusively on human milk often leads to the use of milk-based formula with no prior evaluation of the quality of the human milk being offered.

The present study proposes that the energy content of human milk be assessed immediately before its administration to the newborn infant in an attempt to avoid human milk being abandoned in favor of a milkbased formula with no attempt to improve its caloric and nutritional content.

Although the milk bank at the IFF uses the creamatocrit technique to control the lipid content of their PHM, the milk given to premature newborn infants is often processed at the lactation center after this evaluation has taken place and before it is administered, which may be one explanation for the reduced fat content of these samples.
The issue of insufficient weight gain in VLBW infants justifies the performance of further studies to identify the points at which energy content is lost from PHM and to find solutions to avoid these losses, thus improving conditions for exclusive human milk use.

Simple precautions during the feeding of human milk to the newborn infants can be effective measures for reducing the loss of calories caused by particles of fat clinging to the inside walls of equipment. These include holding syringes vertically, reducing the time taken for infusion of diets to the maximum extent possible and regular homogenization of the milk thereby allowing better calorie supply and, consequently, better weight gain. ${ }^{3}$ Additionally the fat content of the PHM could be stipulated in medical prescriptions.

Evaluation of the caloric content of the milk that actually arrives at the newborn infant and encouragement of the use of milk from the newborn infants own mother, associated with support that permits true maternal breastfeeding, even if not at every feed, could be the best way to deal with issues that have come up recently, such as how to feed eversmaller and more premature newborns thus preparing generations more likely to develop in a healthy way.

\section{References}

1. American Academy of Pediatrics, Work Group on Breastfeeding. Breastfeeding and the use of human milk. Pediatrics. 1997; 100:1035-9.

2. American Academy of Pediatrics \& American College of Obstetricians and Gynecologists. Guidelines for perinatal care. 5th ed. New York: CV Mosby; 2002.

3. Shanler RJ. Suitability of human milk for the low-birthweight infant. Clin Perinatol. 1995;22:207-22.

4. Wang CD, Chu PS, Mellen BG, Shenai JP. Creamatocrit and the nutrient composition of human milk. J Perinatol. 1999;19:343-6.

5. Lucas A, Gibbs JAH, Lyster RLJ, Baum JD. Creamatocrit: simple clinical technique for estimating fat concentration and energy value of human milk. BMJ. 1978;22:1018-20.

6. Shanler RJ, Oh W. Nitrogen and mineral balance in preterm infants fed human milks or formula. J Pediatr Gastroenterol Nutr. 1985;4:214-9.

7. Atkinson SA, Bryan MH, Anderson GH. Human milk feeding in premature infants: protein, fat and carbohydrate balances in the first 2 weeks of life. J Pediatr. 1981;99:617-24.

8. Lucas A. Enteral Nutrition. In: Tsang RC, Lucas A, Uauy R, Zlotkin S, editors. Nutritional needs of the preterm infant scientific basis and practical guidelines. New York: Williams \& Wilkins; 1993. p. 209-23.

9. Dewey KG. Nutrition, growth, and complementary feeding of the breastfed infant. Pediatr Clin North Am. 2001;48:87-105.

10. Schanler RJ. The use of human milk for premature infants. Clin Perinatol. 2001;48:206-19.

11. Haller CA, Simpser E. Breastfeeding: 1999 perspective. Curr Opin Pediatr. 1999;11:379-83.

12. Atkinson SA. Human milk feeding of the micropremie in Nutrition and Metabolism of the micropremie. Clin Perinatol. 2000;27: 235-45.

13. Aksit S, Ozkavin N, Caglayan S. Effect of sucking characteristics on breast milk creamatocrit. Paediatr Perinat Epidemiol. 2002;16:355-60.

14. American Academy of Pediatrics, Committee on Nutrition. Nutritional needs for low birth weight infants. Pediatrics. 1985;75:976-86. 
15. Lemons $P M$, Miller $K$, Eitzen $H$, Strodtbeck $F$, Lemons JA. Bacterial growth in human milk during continuous feeding. Am J Perinatol. 1983;1:76-80.

16. Rede Nacional de Bancos de Leite Humano [site na internet]. Brasília: Ministério da Saúde. Manual técnico; [aproximadamente 12 telas]. Disponível em: http://www.redeblh.fiocruz.br

17. Giugliani ERJ. Rede nacional de bancos de leite humano no Brasil: tecnologia para exportar. J Pediatr (Rio J). 2002;78:183-4.

18. Henderson TR, Fay TN, Hamosh M. Effect of pasteurization on long chain polyunsaturated fatty acid level and enzyme activities of human milk. J Pediatr. 1998;132:876-8.

19. Metha NR, Hamosh M, Bitman J, Wood DL. Adherence of medium-chain fatty acids to tube feeding of human milk during gavage feeding. J Pediatr. 1998;112:474-6.

20. Goes HCA. Caracterização nutricional de leite humano proveniente de banco de leite e a influência do processamento em sua composição [dissertação]. Rio de Janeiro (RJ): UFRJ; 1999.

21. Zoren-Groben DV, Schrijver J, Van Der Berg H, Berger HM. Human milk vitamin content after pasteurization. Arch Dis Child. 1987;62:162-5.

22. Sacramento ADL. Avaliação do processo de manipulação e do conteúdo energético do leite humano administrado em recém natos prematuros nas maternidades públicas do município do Rio de Janeiro [dissertação]. Rio de Janeiro (RJ): IFF/Fiocruz; 2002.

23. Morely R, Lucas A. Randomized diet in the neonatal period and growth performance until 7,5- 8 y of age in preterm children. Am J Clin Nutr. 2000;71:822-8.

24. Premer DM, Georgieff MK. Nutrition for ill neonates. Pediatr Rev. 1999;20:e56-62.

25. Heird WC. The importance of early nutritional management of low-birthweight infants. Pediatr Rev. 1999;20:e43-4.
26. Ehrenkranz RA, Youns N, Lemons JA, Fanaroff AA, Donovan EF, Wright LL, et al. Longitudinal growth of hospitalized very low birth weight infants. Pediatrics. 1999;104:280-9.

27. Lucas $A$. Role of nutritional programming in determining adult morbidity. Arch Dis Child. 1994;71:288-90.

28. Barker DJ, Osmond C, Golding J. Growth in uterus, blood pressure in childhood and adult life, and mortality from cardiovascular disease. BMJ. 1989;298:564-7.

29. Barker DJ, Gluckman PD, Godfrey KM. Fetal nutrition and cardiovascular disease in adult life. Lancet. 1993;341:938-41.

30. Smith L, Bickerton J, Pilcher G, D'Souza SW. Creamatocrit, carbon content, and energy value of pooled banked human milk: implications for feeding preterm infants. Early Hum Dev. $1985 ; 11: 75-80$.

31. Polberger S, Lönnerdal B. Simple and rapid macronutrient analysis of human milk for individualized fortification: basis for improved nutritional management of very-low-birth-weight infants? J Pediatr Gastroenterol Nutr. 1993;17:283-90.

32. Grumach AS, Jeronimo SEI, Hage M, Carneiro-Sampaio MMS. Nutritional factors in milk from Brazilian mothers delivering small for gestational age neonates. Rev Saude Publica. 1993;455:62.

Corresponding author:

Alan Araújo Vieira

Rua Dr. Nilo Peçanha, 43/1001, Ingá

CEP 24210-480 - Niterói, RJ

Brazil

Phone: + 55 (21) 2719.3154

Fax: +55 (21) 2613.1229

E-mail: alanmari@uninet.com.br 